\title{
Die rol van die rekenaar by mondeling
}

Jannie Botha

For many years language teachers regarded the microcomputer as merely a drill-andpractice machine. One of its main disadvantages seemed to be that it could only be used in certain areas of language teaching, and not, for example, in oral work. In this paper it is argued that advances in hardware as well as software now make the microcomputer an all-rounder with regard to language teaching. Not only can the analogue sound storage facilities enhance listening comprehension practice but it can also be used for listening practice for different dialects. Advances in software development, for example simulation programmes, open new possibilities for oral group work. Data base programmes can also be used for gathering and organising information before oral work commences.

It is emphasized in this paper that the microcomputer will not easily become a willing and able partner in real conversation. On the other hand, if one looks at the recent advances in educational technology, an electronic conversation partner may be part of the language teaching scenario sooner than anticipated by language teachers.

Baie jare lank het taalonderwysers die mikrorekenaar net gesien as 'n dril-en oefenmasjien. Dit het gelyk asof een van die hoofnadele van die mikrorekenaar was dat dit net gedeeltelik van toepassing was op taalonderrig en glad nie vir mondelinge werk bruikbaar was nie. In hierdie artikel word beweer dat onlangse ontwikkelinge in beide apparatuur en programmatuur verseker dat die mikrorekenaar in alle fasette van taalonderrig gebruik kan word. Nie net kan die analogie - bergingsfasiliteit vanklank luisterbegrip bevorder nie, maar dit kan ook gebruik word in luisterbegrip t.o.v. verskillende dialekte. Verdere ontwikkelinge in programmatuur, bv. simulasieprogramme, skep nuwe moontlikhede vir mondelinge groepwerk. Databasisprogramme kan ook gebruik word om inligting te versamel en te organiseer voordat mondelinge werk ' $n$ aanvang neem.

Hierdie artikel beklemtoon die feit dat die mikrorekenaar nog nie maklik'n gewillige en bekwame vennoot in gewone geselskap sal wees nie. Aan die ander kant, as 'n mens onlangse ontwikkeling in die opvoedkundige tegnologie in gedagte hou, is dit moontlik dat 'n elektroniese geselsmaat dalk vroeër as wat verwag is, deel sal uitmaak van die taalonderwysscenario. 


\section{Inleiding}

Baie taalonderwysers ${ }^{1}$ vra tereg die vraag: Hoe kan ek die rekenaar gebruik in my onderrigprogram? Dit is myns insiens nie ' $n$ onregverdige vraag nie. Nie baie jare gelede nie, is 'n soortgelyke vraag oor die taallaboratorium of selfs oor die truprojektor gevra.

'n Mens kan onderwysers die vraag oor die toepaslikheid van die rekenaar nie verkwalik nie. Vir die afgelope twee dekades reeds word die mikrorekenaar (of selfs die hoofraamrekenaar) voorgehou as 'n uitstekende dril- en oefenmasjien. Gedurende hierdie tydperk het baie min mense werklik getwyfel aan die rekenaar ${ }^{2}$ se vermoë om oefenwerk te beheer. Om die waarheid te sê, enigiets wat deur vaste reëls beheer word, kan deur die rekenaar hanteer word. Dit is egter juis by hierdie vaste reëls dat onderwysers vasgesteek het: almal weet tog dat taal nie so logies is en honderd persent deur vaste reëls beheer word nie. Hoe kan die rekenaar dan vir taalonderrig gebruik word?

Enigeen wat meer intensief na die moontlikhede van die rekenaar kyk, sal opmerk dat die sogenaamde beperkings waarvan die apparaat beskuldig word, nie noodwendig voor die deur van die apparaat self gelê moet word nie. Dit beteken nie dat die rekenaar slegs geskik is vir driloefeninge nie. Dit beteken wel dat interessanter take heelwat meer tyd en energie verg van die ontwerpers van lesse. Dit is miskien die werklike rede waarom die rekenaar en die programme wat beskikbaar is, as oninteressant en swak gestruktureerd beskou is en word.

Ten spyte van die donker prentjie wat u nou mag begin vorm oor die rekenaar in taalonderrig, beweer Leonard (1985:13-14) dat daar wonderlike moontlikhede is vir die gebruik van die rekenaar in hierdie vakgebied. Dit hang juis saam met die groter buigbaarheid wat eie geword het aan rekenaars in die afgelope paar jaar. In die meeste gevalle lê die beperkings nie meer by die rekenaar nie maar in die verbeeldingrykheid - of gebrek daaraan - van die taalonderwyser.

Soos die rekenaar groei in terme van geheue en bergingskapasiteit (weliswaar kleiner in voorkoms) kom daar allerlei nuwe moontlikhede na vore. In terme van lees- en skryfaktiwiteite kan die rekenaar feitlik reedsalle moontlikhede hanteer. Die moontlikhede in hierdie verband wissel tussen die enge $A / B / C / D$ van veelvuldige keuse-vrae aan die eenkant tot die vryheid van die woordverwerker aan die anderkant. Selfs die elementêre ontleding van sinne is nie uitgesluit nie.

Vir die doel van hierdie bespreking, is die vraag of die rekenaar ook ' $n$ bydrae tot die onderrig van die mondelingprogram kan lewer. (Dit word veronderstel dat die mondelingprogram nie losstaande is van die ander taalaktiwiteite nie.) Een van die grootste moontlikhede van die rekenaar is juis die vermoë om die stimulering vir die ontwikkeling van die mondelinge vaardighede te verskaf. Hiermee word nie gespekvoering tussen die rekenaar en die leerling bedoel nie maar tussen die leerlinge onderling as gevolg van die stimulering deur 'n rekenaarprogram.

\section{Die rekenaar in die mondelingprogram}

Een van die probleme waarmee taalonderwysers te doen kry, veral in groot klasse, is om gesprekke tussen leerlinge in groepe aan die gang te hou. Selfs as die onderwerp onder bespreking interessant is, kan dit gebeur dat die gesprek redelik gou opdroog en dat

1 Die term "onderwyser" sluit ook "onderwyseresse" in.

2 Rekenaar $=$ mikro- sowel as hoofraamrekenaars. 
leerlinge nie weet wat om verder te sê nie.

Die rekenaar kan die werk van 'n gesprekspromotor speel deur materiaal te verskaf waarop die leerlinge kan reageer. Dit kan hulle help om op die onderwerp te fokus sowel as om nuwe idees te verskaf waarop hulle kan reageer.

\subsection{Luisterbegrip}

' $n$ Moontlikheid wat nog nie ontgin is met die oog op taalonderrig nie, is die verbinding van die rekenaar aan ander randapparatuur. ' $n$ Gewone kassetspeler kan gebruik word om luisterbegrip te toets - en hoe belangrik is dit nie dat leerlinge geleer word om te luister nie! Deur die kassetspeler deur middel van die rekenaarprogram te beheer, kry die leerling kans om, indien hy/sy verkeerd geantwoord het, weer na die betrokke gedeelte te luister en dan weer die vraag te beantwoord. Met die beskikbaarstelling van groot hardeskywe word die moontlikhede van gesofistikeerde en gevorderde luisteroefeninge wat deur die rekenaar beheer word, ' $n$ al groter werklikheid. Dit is nou reeds moontlik om tot soveel as vier uur se klank op 'n 20 Megagreep-hardeskyf te berg. Dit is heelwat meer as wat ' $n$ mens vir een dag se lesse sal nodig hê.

Die voordeel van klank op die hardeskyf is dat dit op 'n willekeurige basis en in enige volgorde teruggeroep kan word. In die geval van 'n kassetspeler is die klank lineêr geberg en kan dit ook net in 'n spesifieke volgorde teruggeroep word hoewel die band tot by ' $n$ sekere punt gedraai word. Deur die aanbring van 'n goedkoop analoogkaart in die rekenaar kan klank deur middel van 'n mikrofoon (bv. toesprake) op die hardeskyf opgeneem word. Dit is egter ook moontlik om klank vanaf 'n kassetspeler na die hardeskyf oor te dra.

Sodra die klank op die hardeskyf geberg is, is die moontlikhede vir luistebegrip feitlik onbeperk. Deur vir die leerling 'n paragraaf te speel, kry hy die geleentheid om te luister en vrae te beantwoord. In geval van 'n verkeerde antwoord, kry hy kans om weer na die betrokke deel te luister en dan weer die vraag te probeer beantwoord. Op die rekenaar is dit moontlik om dieselfde vraag die tweede keer in ander woorde te stel. Sodoende kry die leerling kans om die regte antwoord te verskaf op grond van luisterbegrip en nie op grond van vraag-herkenning nie.

Die gebruik van die rekenaar vir basiese luisterbegripoefeninge is slegs een van die moontlikhede wat tans beskikbaar is. 'n Ander moontlikheid is die gebruik van verskillende streekdialekte. Deur die leerling aan streekdialekte bekend te stel en dan vrae daaroor te vra, word die waarde van luisterbegrip aansienlik uitgebrei.

\subsection{Spraak en praat}

Soos reeds vroeër aangedui, is die moontlikheid van die rekenaar om as gespreksgenoot op te tree, in hierdie stadium baie beperk en uiters primitief. Die sogenaamde ruimte eeu-klank wat tans deur selfs die beste rekenaars gelewer word, wat klink na geblikte bowe-aardse klanke, is nog totaal onaanvaarbaar vir taalonderwysers.

Dit sal nog 'n geruime tyd neem alvorens 'n rekenaar 'n gesprek kan saamstel uit normale, menslike spraak wat êrens in die rekenaar geberg word. Die ideaal is egter dat die rekenaar 'n klank-databasis kan raadpleeg en sinne op daardie manier kan saamstel. Dit is maar een deel van die probleem. Die anderkant is dat die rekenaar nie alleen die regte woorde vir 'n gesprek moet kan uitsoek nie, maar ook die 
moontlikheid sal hê om die korrekte intonasie en ritme-patrone aan die sin toe te ken. Dit is afgesien daarvan dat die rekenaar nog nie 'n goeie luisteraar is wat die spraak van ' $n$ mens kan verstaan en interpreteer nie. U sien dus dat kunsmatige intelligensie, sover dit spraak aangaan, nog nie ver gevorder het sedert kunsmatige onintelligensie nie!

\subsection{Simulasie en rolspel}

Aangesien die rekenaar bekend is vir sy onvermoeide vermoë om data te manipuleer, bied dit verskeie moontlikhede om as gesprekspromotor of -stimuleerder gebruik te word (Kecskés 1988:33-35).

Kommunikasieprogramme is bedoel om gesprekke in die klaskamer te stimuleer deur die leerlinge sowel as die onderwyser te betrek. Daar bestaan nie 'n oorvloed van hierdie programme nie maar dié wat wel beskikbaar is (in Engels of ander Europese tale) maak gebruik van lewensgetroue situasies. Dit haal tot 'n mate die kunsmatigheid uit rekenaargebaseerde taalonderrig (RGTO) uit.

'n Voorbeeld van 'n situasie waarin 'n program gebruik kan word, is die volgende: In ' $n$ redaksiekantoor is daar ' $n$ vakature vir 'n senior verslaggewer. Daar is drie kandidate vir die pos. Die rekenaarprogram beskik oor die informasie van elkeen ten opsigte van sy persoonlike besonderhede, kwalifikasies, vorige ondervinding, houding en karaktereienskappe. Alhoewel die rekenaar se woordeskat beperk is, kan vrae in 'n groot verskeidenheid vorme gevra word. Om die waarheid te sê, sodanige programme kan feitlik enige vraagstruktuur hanteer. As die vraag semanties sowel as grammatikaal korrek is, sal die rekenaar ' $n$ antwoord op die skerm verskaf. Die doel van die program is dat die leerlinge moet besluit wie aangestel sal word op grond van die inligting wat die rekenaar beskikbaar stel. Dit is dus duidelik dat leerlinge heelwat bespreking sal moet voer alvorens elke vraag gevra word, oor die wyse waarop die vraag gestel word sowel as oor die inligting wat die rekenaar in sy antwoord verskaf. Indien hulle byvoorbeeld 'n ondeurdagte vraag stel, sal die rekenaar se antwoord langs dieselfde lyne wees. Dit bly egter ' $n$ vraag hoe die rekenaar dubbelsinnige vrae sal interpreteer.

Hierdie program, wat deur Kecskés beskryf word, is ontwikkel met die hulp van kunsmatige intelligensie-tegnieke. Daar is egter verskeie probleme wat nog nie opgelos kon word nie. So is dit vir die rekenaar verstaanbaar as iemand sou vra "What is Jack like?", maar nié as die vraag "What about Jack?" is nie, dit wil sê, vrae wat op voorafgaande (nie verskafde) inligting gebaseer is. Die program maak dus nog nie voorsiening vir vrae wat gebaseer is op informasie wat vroeër bekom is nie.

Voorts moes voorsiening gemaak word vir vrae wat op verskillende maniere geformuleer kan word. Dit is moontlik om te vra of Jack getroud is, of hoe lank Jack reeds getroud is. In die tweede geval, moet die program weet of Jack wel getroud is (veronderstelde inligting) en dan vasstel hoe lank hy getroud is.

Die voorafgaande uiteensetting was bedoel om ' $n$ aanduiding te gee van hoe moeilik dit is om 'n program te ontwerp wat op die verskillende moontlikhede van byvoorbeeld vraagstelling kan reageer. Aan die anderkant toon dit egter dat daar interessante verwikkelinge is waarmee vorentoe rekening gehou kan word.

In die voorafgaande beskrywing van 'n kommunikasieprogram is aangetoon hoe 
daar gepoog is om die rekenaar as gespreksgenoot te betrek. Die rekenaar was 'n deelnemer aan die gesprek in soverre as wat dit die leerlinge se vrae beantwoord het.

Dit is egter ook moontlik om die rekenaar as verskaffer en verwerker van data te gebruik ten einde die gesprek tussen die leerlinge aan die gang te sit en te hou. Sodoende word die rekenaar die onderhouer van die gesprek hoewel dit self nie kan praat nie. Soos Jones en Fortescue dit stel: "Computer simulations can provide a motivating stimulus for such work [free oral activities], as they offer both a focus for oral activity and a continually changing scenario for learners to talk about." (1987:63). Hierdie skrywers noem meer as een voorbeeld van goeie simulasieprogramme wat reeds suksevol gebruik is vir mondelinge werk. Hier sal gekonsentreer word op een hiervan, nl. die Yellow River Kingdom.

Die aktiwiteite rondom hierdie program kan in drie dele verdeel word, $\mathrm{nl}$. voorbereiding vir gebruik van die program, die aktiwiteite self en terugvoering.

Gedurende die voorbereiding verduidelik die onderwyser die program aan die leerlinge. In hierdie stadium kan besluit word of die program vir simulasie of rolspel gebruik sal word. Dit bepaal onder andere die aard van die taalgebruik wat nodig sal wees. In ' $n$ simulasie is die leerlinge net hulleself terwyl hulle in 'n rolspel 'n ander identiteit aanneem. Vir die rolspel sal sekere taalregisters vooraf verduidelik moet word, bv. formele taalgebruik, maniere van opsom, ontleding van feite, ens. Nadat hierdie voorbereidings afgehandel is, word die volgende fase aangepak.

In die aktiwiteite word die leerlinge in groepe verdeel en elke groep werk deur die program teen sy eie tempo. Hierdie aktiwiteit moet sorgvuldig deur die onderwyser gekontroleer word. Omdat leerlinge met' $n$ beperkte taal en woordeskat kan regkom, is die versoeking om slegs beperkte taal te gebruik, bv opdragte of eenwoord-sinne.

\subsection{Beskrywing van die program:}

Die Yellow River Kingdom is 'n hertogdom wat aan 'n sekere rivier geleë is. Dit bestaan uit drie dorpies wat tussen die rivier aan die weste en die berg aan die ooste geleë is. ' $n$ Dyk word gebruik om die vloei van water na die lande te beheer. Aan die anderkant is daar rowerbendes in die berge wat weer die lewens van die inwoners bedreig.

Die heerser van hierdie hertogdom het slegs twee bronne van sekuriteit, nl. die bevolking wat in die lande kan werk en 'n aantal sakke graan wat vir kos sowel as aanplanting gebruik moet word. Daar is drie seisoene in hierdie land, nl. winter, 'n groei-seisoen en 'n oesseisoen. Aan die begin van 'n seisoen moet die heerser besluit hoe hy sy bronne gaan benut: hoeveel mense moet in die lande werk, hoeveel moet die dyk beman en hoeveel moet die oeste beskerm teen die rowerbendes.

Die toewysing van die mense is uiters belangrik. Indien die dyk onderbeman is, kan die lande oorstroom en al die oeste vernietig word. Indien te min mense die dorpies bewaak, kan die rowerbendes die voedselvoorraad steel. As daar nie genoeg mense in die lande is nie, kan dit 'n swak oes met die gevolglike hongersnood veroorsaak.

In elke groeiseisoen moet daar ook besluit word hoeveel graan geplant moet word. Dit het weer 'n uitwerking op die oes wat verwag kan word asook hoeveel graan oor is vir gebruik deur die bevolking. 
Aan die begin van 'n sessie moet al die informasie oor die besluite in die rekenaar ingevoer word. Voorafgaande aan hierdie punt behoor die mondelinge vaardighede en gesprekvoering tot sy reg te kom. Dit is ook hier waar taalregister 'n belangrike rol speel. Nadat die informasie ingevoer is, kan die heerser (d.w.s. die groep leerlinge) sit en kyk wat die gevolge van hulle besluite is. Die gevolge is nie uitsluitlik aan die besluite van die groepe gekoppel nie maar ook aan sekere waardes wat deur die rekenaar op ' $n$ willekeurige basis aan veranderlikes toegeken word. ' $n$ Kombinasie van hierdie twee faktore verseker dat die resultate elke keer verskillend is.

Een manier om hierdie simulasie beter te benut uit die oogpunt van mondelinge werk, is om rolle aan die verskillende leerlinge toe te ken, d.w.s. om oor te skakel na 'n rolspeel-situasie. So kan daar byvoorbeld ' $n$ kabinet saamgestel word met die volgende poste: Eerste Minister, Ministers van Landbou, Verdediging, Waterwese en Staatsdiens. Die bekleërs van elkeen van hierdie poste is verantwoordelik om, in oorleg met sy raadgewers (die res van die leerlinge), besluite te neem en die relevante informasie in die rekenaar in te voer.

Dit mag nodig wees om die rolspel nie direk voor die rekenaar te laat plaasvind nie. Dit mag selfs nodig wees om die deelnemers in 'n ander vertrek te laat beraadslaag. Sodoende word die gevaar van beperkte spraak (bv een-sin uitings) teengewerk. Sodoende word die omvang sowel as die kwaliteit van die spraak verbeter. Dit is veral belangrik dat die onderwyser toesig hou oor die beplanning ten einde die leerlinge aan te moedig tot goeie en verstaanbare taalgebruik, sowel as tot helder, logiese taalgebruik.

Die terugvoer-fase is net so belangrik soos die voorbereiding. Gedurende hierdie sessie kry groepe kans om aan mekaar te vertel wat gebeur het en hoe hulle gevaar het in die bestuur van die hertogdom. Hierdie ervarings kan later in 'n skryfaktiwiteit saamgevat word, bv. ' $n$ verslag waarin al die bevindings uiteengesit word en waarin aanbevelings gemaak word.

Gedurende die terugvoering moet die onderwyser ook vir die leerlinge 'n evaluering gee van die taal wat hulle gebruik het. Dit is ook die geleentheid vir die leerlinge om op mekaar se taalgebruik kommentaar te lewer asook om vrae te vra oor woordeskat of taalstrukture waaroor daar twyfel bestaan.

\subsection{Ander moontlikhede}

Iemand mag tereg vra: Waar kry mens so 'n simulasie-program, en dit nogal in Afrikaans? Dit is natuurlik moontlik om ' $n$ Engelse weergawe van 'n simulasie aan te koop en dit van data in Afrikaans te voorsien. Sodanige simulasie-programme kos gewoonlik nie ' $n$ plaas se prys nie. Dit is egter wenslik om 'n beproefde program te koop en te verseker dat daar' $n$ redigeerder ingesluit is waarmee 'n leerkrag (of groep leerkragte) maklik eiesoortige data kan invoeg.

Daar is egter ' $n$ ander interessante moontlikheid wat nie oor die hoof gesien moet word nie. Dit is die gebruik van 'n databasis-program (bv. soos die een wat gebruik word vir die hou van informasie oor die leerlinge in die skool). Eers moet onderwysers ' $n$ groot klomp data in die program plaas sodat daar genoeg is vir verskillende leerlinge om dit te gebruik vir navorsing oor 'n onderwerp. Die volgende voorbeeld mag onderwysers idees gee vir so 'n program: Verkry inligting 
oor al die politieke leiers in Suid-Afrika sedert die begin van die eeu. Dit sluit inligting in oor hulle name, afkoms, goeie hoedanighede, swak hoedanighede, politieke affiliasies, lewensverloop, ens. Deur al hierdie inligting in 'n databasis te plaas, word ' $n$ feitlik onuitputbare bron van informasie vir leerlinge se mondelingonderwerpe geskep. Deur die informasie beskikbaar te stel soos leerlinge dit benodig, kan verskillende aspekte van 'n onderwerp sinvol bespreek word.

Die blote feit dat leerlinge informasie oor 'n onderwerp elektronies kan verkry, gee 'n motiveringswaarde aan mondeling-werk wat dikwels ontbreek. Die "projek" sou baie eensydig wees as leerlinge net inligting uit die databasis kon onttrek. Hulle behoort ook tœegelaat te word om inligting in die databasis aan te vul of selfs te korrigeer. Sodoende word 'n klasprojek aan die gang gesit waarvan een van die voordele onderwerpe vir mondelinge is maar waarin leerlinge ook geleer word om informasie te onttrek en sistematies te orden vir ' $n$ toespraak in die klas. Hierdie benadering gee, myns insiens, ' $n$ werklikheidswaarde aan mondeling-werk. Dit is 'n vaardigheid wat leerlinge ook ná hulle skoolloopbane kan gebruik want dit sluit aan by die aanwending van taal vir die oplossing van probleme, dit wil sê, intelligente taalgebruik.

Wanneer 'n rekenaar vir hierdie doel gebruik word, het 'n skool ook nie 'n veelvoud van rekenaars nodig nie. Een of twee rekenaars is voldoende om so 'n databasis mee op te bou. Aangesien heelwat leerlinge ook toegang tot rekenaars by hulle huise het, kan die projek in groepverband (binne perke) ook ná skool voortgesit word.

Die rekenaar kan ook aan ' $\mathrm{n}$ skyfieprojekter gekoppel word ten einde basiese mondelinge werk te doen. Sodoende word ' $n$ visuele element bygevoeg waardeur die mondelinge vaardigheid gestimuleer word.

\section{Toekomsblik}

Dit is altyd goed om, wanneer 'n mens oor die tegnologie in taalonderrig praat, ook vorentoe te kyk en te spekuleer wat moontlik vir ons wag. As 'n mens kyk na die geweldig vinnige ontwikelingfases wat die tegnologie die afgelope vyf tot tien jaar deurgegaan het, dan is die tegnologiese toekoms eintlik nader as wat jy dink.

Soos reeds vroeër gesê, sal dit nog ' $n$ rukkie neem voordat ' $n$ rekenaar ' $n$ sinvolle gespreksgenoot vir 'n mens kan wees. Die sogenaamde "intelligente gesprek" van ELIZA die sielkundige (reeds bekend uit die sestigerjare), word hier buite rekening gelaat.

Die gebied van interaktiewe video vir die stimulering van mondelinge werk, open egter interessante moontlikhede. Een van die interessantste programme is seker Montevidisco (Brigham Young Universiteit). Dit is die verhaal van 'n reisiger wat 'n besoek bring aan Meksiko. Op grond van vrae wat die besoeker aan die rekenaar vra, verander die videoskerm (vertakkings). Die reisiger kan deur die verkeerde vrae vir 'n polisieman te vra byvoorbeeld, in die tronk beland in plaas van by die operahuis uitkom. Hierdie program is, soos verwag kan word, teen hoë koste ontwerp en vervaardig, en dit is ook toegespits op tweedetaalonderrig (nl. Spaans).

Daar kan dus beweer word dat die rekenaar ' $n$ rol te speel het in die mondelingprogram, mits daar nie in hierdie stadium te veel van die apparaat verwag word nie en die voor die hand liggende moontlikhede wat dit reeds bied, nie misgekyk word nie. 


\section{Bibliografie}

KECSKÉS, I. 1988. Computer programs to develop both accuracy and fluency. SYSTEM 16(1), 29-35.

LEONARD, J. 1985. Computers in language and literacy work. London: Adult Basic Skills Unit.

JONES, C., FORTESCUE, S. 1987. Using computers in the language classroom. London: Longman. 